FIOREZE et al., v(10), no 10, p. 2251-2265, JAN-ABR, 2013.

Rev. Elet. em Gestão, Educação e Tecnologia Ambiental (e-ISSN: 2236-1170)

\title{
GÁS NATURAL: POTENCIALIDADES DE UTILIZAÇÃO NO BRASIL
}

\author{
Mariele Fioreze ${ }^{1}$, Keila Fernanda Soares Hedlund ${ }^{2}$, Cristiane Graepin ${ }^{3}$, Tainara Casa Nova Silva ${ }^{4}$, \\ Francéllwika Catharine Gomes de Azevedo ${ }^{5}$, Pedro Daniel da Cunha Kemerich ${ }^{6}$ \\ ${ }^{1}$ Universidade Federal de Santa Maria - UFSM/CESNORS. E-mail: mariele.fioreze@gmail.com, \\ ${ }^{2}$ Universidade Federal de Santa Maria - UFSM/CESNORS. E-mail: keilahedlund@hotmail.com, \\ ${ }^{3}$ Universidade Federal de Santa Maria - UFSM/CESNORS. E-mail: cristianegraepin@ hotmail.com, \\ ${ }^{4}$ Universidade Federal de Santa Maria - UFSM/CESNORS. E-mail: tai.cns@hotmail.com, \\ ${ }^{5}$ Universidade Federal de Santa Maria - UFSM/CESNORS. E-mail: francellwika@gmail.com, \\ ${ }^{6}$ Universidade Federal de Santa Maria - UFSM/CESNORS. E-mail: pdck@pop.com.br.
}

http://dx.doi.org/10.5902/223611707896

\section{RESUMO}

O mercado de gás natural para produção de energia vem crescendo consideravelmente no Brasil, apoiado nas vantagens ambientais e tecnológicas deste energético. Apesar dos registros históricos, que indicam que o gás natural já era utilizado no Irã entre 6000 e 2000 anos a.C, este só foi introduzido no mercado Europeu em 1659 e, ainda mais tardiamente, começou a ser utilizado no Brasil apenas por volta de 1940, devido às descobertas de óleo e gás na Bahia. Atualmente, este energético vem ganhando cada vez mais espaço, devido principalmente às exigências ambientais, a construção do gasoduto Bolívia-Brasil e as descobertas da camada Pré-Sal na Bacia de Santos. Semelhantemente ao petróleo, o gás natural tem sua formação associada à decomposição de vegetais e animais em ambiente com pouco oxigênio e condições de elevadas temperatura e pressão. Consiste numa combinação de hidrocarbonetos leves e gasosos, em especial o metano, e possui menor impacto ambiental que o petróleo e o carvão. É considerado como um combustível de transição, sendo sua utilização necessária até que se desenvolvam alternativas tecnológicas viáveis e de baixo impacto ambiental para o fornecimento de energia.

Palavras-chave: Combustíveis fósseis. Energia elétrica. Gás natural.

\begin{abstract}
The market for natural gas for electric power generation has increased considerably in Brazil, supported by the environmental and technological advantages of this energy. Despite the historical records that indicate that natural gas was already being used in Iran between 6000 and 2000 B.C, this was only introduced in the European market in 1659, and still later, began to be used in Brazil, only around 1940 due to oil and gas discoveries in Bahia. Currently, this energy is gaining more space, mainly due to environmental requirements, the construction of the BoliviaBrazil pipeline and the discoveries of Pre-Salt layer in the Santos Basin. Similarly to oil, the natural gas has its training associated with decomposition of plants and animals in an environment with low oxygen conditions and high temperature and pressure. It's a combination of light hydrocarbons and gases, particularly methane, and has lower environmental impact than oil and
\end{abstract}




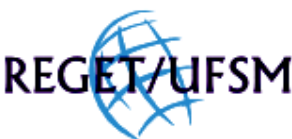

FIOREZE et al., v(10), no 10, p. 2251-2265, JAN-ABR, 2013.

Rev. Elet. em Gestão, Educação e Tecnologia Ambiental (e-ISSN: 2236-1170)

coal. It is considered as a transition fuel, and their use until needed to develop alternative technologies with low environmental impact for the power supply.

Key-words: Fossil fuels. Electricity. Natural gas.

\section{INTRODUÇÃO}

A vida da maioria das pessoas, em maior ou menor escala, depende da eletricidade. No Brasil, os últimos anos foram caracterizados por acontecimentos importantes ligados ao setor elétrico, os quais permitiram o surgimento de inúmeras frentes de pesquisa e outras iniciativas que, entre outros, estudam o planejamento da expansão da oferta de energia no Brasil, o que inclui o estudo do potencial advindo do uso do gás natural (PARO, 2005).

A discussão sobre as fontes com potencial para satisfazer as necessidades energéticas sempre trás a tona também às questões ambientais e impactos gerados na utilização. Visto à necessidade de reduzir os problemas associados à queima de combustíveis fósseis, principalmente o petróleo e o carvão que são as principais fontes de emissão de $\mathrm{CO}_{2}$, fontes energéticas diversificadas surgem como alternativas para suprir as demandas necessárias à continuidade do desenvolvimento econômico e social. Dentre os combustíveis fósseis, o gás natural é considerado o mais limpo e menos intensivo em carbono, daí a sua importância como combustível de transição, até que se desenvolvam alternativas tecnológicas de baixo impacto ambiental (VIEIRA et al., 2005).

De forma geral, pode-se dizer que o mercado de gás natural é recente. $A$ ingressão deste energético como atividade econômica no cenário mundial se deu no início do século XX, desenvolvendo-se irregularmente nas diversas regiões do planeta (LAUREANO, 2002). Já o uso do gás natural como fonte de suprimento energético se deu principalmente a partir dos choques do petróleo, ocorridos nos anos de 1973 e 1979, caracterizados pela elevação dos preços provocada pela Organização dos Países Exportadores do Petróleo (OPEP), que levou as grandes potências consumidoras a diversificarem seus suprimentos de energia (GOMES, 1996). Esses eventos alertaram sobre a necessidade da diversificação das fontes energéticas, a fim de diminuir a vulnerabilidade dos países associada a choques de oferta de petróleo, conjuntura esta que, entre outros, impulsionou o uso de hidrocarbonetos gasosos (MATHIAS, 2008).

O gás natural é definido como sendo a parcela do petróleo que se encontra na fase gasosa ou em solução nas condições de reservatório e que permanece no estado gasoso nas condições atmosféricas (PARO, 2005; SANTOS et al., 2007). É oriundo da combinação de hidrocarbonetos leves e gasosos, com preponderância das moléculas de metano $\left(\mathrm{CH}_{4}\right)$, podendo conter também, em menores quantidades, os gases etano $\left(\mathrm{C}_{2} \mathrm{H}_{6}\right)$, propano $\left(\mathrm{C}_{3} \mathrm{H}_{8}\right)$, butano $\left(\mathrm{C}_{4} \mathrm{H}_{10}\right)$, entre outros (KOZERSKI \& HESS, 2006; SANTOS et al., 2007). Porém, é importante ressaltar que a composição do gás natural varia conforme sua origem geológica (REIS et al., 2005).

O gás natural possui origem semelhante à do carvão e do óleo. É resultado do lento processo de decomposição de vegetais e animais em ambiente com pouco oxigênio e condições de elevadas temperatura e pressão (REIS et al., 2005). Corresponde hoje a terceira maior fonte de energia fóssil primária no mundo, logo após o petróleo e o carvão (SANTOS et al., 2007).

No Brasil, o uso do gás natural para produção de energia tem aumentado consideravelmente nos últimos anos desde a última década. As prioridades definidas pelo 


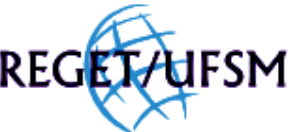

FIOREZE et al., v(10), no 10, p. 2251-2265, JAN-ABR, 2013.

Rev. Elet. em Gestão, Educação e Tecnologia Ambiental (e-ISSN: 2236-1170)

Governo Federal quanto à utilização do gás natural contemplam a reinjeção nos poços de produção de petróleo, uso como matéria prima na indústria petroquímica e de fertilizantes e a substituição de gás liquefeito de petróleo (GLP) e nafta (GOMES, 1996). Com o esgotamento dos melhores potenciais hidráulicos do país e a construção do gasoduto Bolívia-Brasil, o gás natural tornou-se uma escolha importante para a imprescindível ampliação da competência de geração de energia elétrica (ANEEL, 2005).

A expansão do mercado de gás natural se deve muito à melhoria nas cotações deste energético. As grandes reservas de gás não convencional nos EUA e Canadá tornaram atrativos os preços desse insumo, de forma a dar inicio a transição de uma economia do petróleo para uma economia de energias sustentáveis, mudança essa que no Brasil está apoiada sobre as descobertas do Pré-Sal (GOMES, 2011).

De acordo com o tema exposto, o presente trabalho visa apresentar as potencialidades de uso do gás natural, suas fontes e origem, além de expor o cenário atual do mercado de gás natural brasileiro.

\section{GÁS NATURAL}

\subsection{Conceituação}

O gás natural (GN) vem sendo utilizado pelo homem desde a antiguidade. Registros remotos mostram que sua descoberta ocorreu no Irã entre 6000 e 2000 a.C. (FERREIRA, 2006). Ainda conforme o autor, o GN já era conhecido na China desde 900 a.C., mas foi em 211 a.C. que o país começou a extrair a matéria-prima com o objetivo de secar pedras de sal, utilizando varas de bambu para retira-lo de poços com profundidade aproximada de 1000 metros.

Na Europa, o gás natural só foi descoberto no ano de 1659, não despertando interesse por causa da grande aceitação do gás resultante do carvão carbonizado (town gás), que foi o primeiro combustível responsável pela iluminação de casas e ruas desde 1790 (SANTOS et al., 2002). Já nos Estados Unidos, o primeiro gasoduto com fins comerciais entrou em operação na cidade de Fredonia, no estado de Nova York, em 1821, fornecendo energia aos consumidores para iluminação e preparação de alimentos (FERREIRA, 2006).

O gás natural é um combustível fóssil, não renovável, encontrado em reservatórios subterrâneos tanto em terra quanto em mar. É definido como sendo a parcela do petróleo que se encontra na fase gasosa ou em solução nas condições de reservatório e que permanece no estado gasoso nas condições atmosféricas (BRAGA et al., 2005; PARO, 2005; SANTOS et al., 2007). Sua composição é dada por uma mistura variada de hidrocarbonetos leves, em principal o metano $\left(\mathrm{CH}_{4}\right)$, etano $\left(\mathrm{C}_{2} \mathrm{H}_{6}\right)$, propano $\left(\mathrm{C}_{3} \mathrm{H}_{8}\right)$ e butano $\left(\mathrm{C}_{4} \mathrm{H}_{10}\right)$, podendo ser encontrado na forma associada, em poços petrolíferos e, principalmente, na forma não associada, em reservatórios de gás, onde a exploração se torna mais favorável (BRAGA et al., 2005; FERREIRA, 2006; PARO, 2005). Igualmente ao petróleo, os depósitos de GN são encontrados em formações geológicas nas quais as misturas de gases foram presas por uma massa de rocha impermeável (BAIRD \& CANN, 2011). Os processos naturais de formação do $G N$ envolvem a degradação da matéria orgânica por bactérias anaeróbias, a degradação da matéria orgânica e do carvão por temperatura e pressão elevadas e a alteração térmica dos hidrocarbonetos líquidos (VIEIRA et al., 2005). Geralmente apresenta baixos 


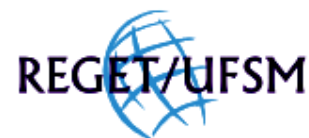

FIOREZE et al., v(10), no 10, p. 2251-2265, JAN-ABR, 2013.

Rev. Elet. em Gestão, Educação e Tecnologia Ambiental (e-ISSN: 2236-1170)

teores de contaminantes, como nitrogênio, dióxido de carbono, água e compostos de enxofre (ARRUDA, 2009).

O petróleo e o gás natural possuem origem semelhante. Ambos são compostos pela mistura de hidrocarbonetos originados de pequenas frações de organismos marinhos e plantas que foram retirados da presença do oxigênio, sendo suas formações resultado do acúmulo de energia solar sobre matérias orgânicas soterradas a grandes profundidades (BAIRD \& CANN, 2011). Assim, as elevadas temperaturas e pressões às quais esses materiais enterrados foram submetidos contribuíram para sua decomposição posterior para formar hidrocarbonetos líquidos e gasosos. Apresenta inúmeras vantagens em relação aos demais combustíveis fósseis, principalmente no que se refere ao meio ambiente, como a baixa presença de contaminantes e o fato de seu processo de queima gerar baixo teor de óxido de enxofre (PRAÇA, 2003).

A matéria orgânica fóssil também pode ser chamada de querogêneo. Desta forma, se divide em dois tipos: querogêneo seco, proveniente de matéria vegetal, e querogêneo gorduroso, proveniente de algas e material animal (FERREIRA, 2006). No processo de formação do planeta, as transformações da matéria orgânica vegetal, celulose e lignina, produziram o querogêneo seco, o qual ao alcançar maiores profundidades na crosta terrestre sofreu processo gradual de cozimento, transformando-se em linhito, carvão negro, antracito, xisto carbonífero e metano, dando origem às reservas de carvão do planeta (POULALLION, 1986). Já o querogêneo gorduroso não sofreu processo de cozimento, dando origem ao petróleo (ROCHA, 2002).

A formação do gás natural continua a ocorrer na natureza até os dias de hoje. Porém, devido ao fato de as atuais movimentações da crosta terrestre serem escassas, a velocidade com que novas quantidades são geradas se torna desprezível (FERREIRA, 2006). Por esta razão diz-se que as acumulações deste produto são não renováveis (ABREU \& MARTINEZ, 1999).

No que diz respeito à sua origem, o GN pode classificado como gás associado e como gás não associado (Figura 1). O gás associado ocorre quando há a predominância do petróleo na exploração da jazida, sendo o gás separado durante o processo de produção, passando este a ser considerado um coproduto, enquanto que o gás não associado é obtido em extensas quantidades diretamente do reservatório, sendo pequena a parcela de produção de petróleo (VIEIRA et al., 2005). O gás não-associado apresenta os maiores teores de metano, enquanto que o gás associado apresenta porções mais significativas de etano, propano, butano e hidrocarbonetos mais pesados (SANTANA, 2006). O GN pode ainda ser denominado como gás úmido, quando frações líquidas de hidrocarbonetos comercialmente recuperáveis estão presentes, e de gás seco, quando se tem a fração líquida retida depois de processado na Unidade de Processamento de Gás Natural (UPGN) (VIEIRA et al., 2005). 


\section{REGETATFSM}

FIOREZE et al., v(10), no 10, p. 2251-2265, JAN-ABR, 2013.

Rev. Elet. em Gestão, Educação e Tecnologia Ambiental (e-ISSN: 2236-1170)

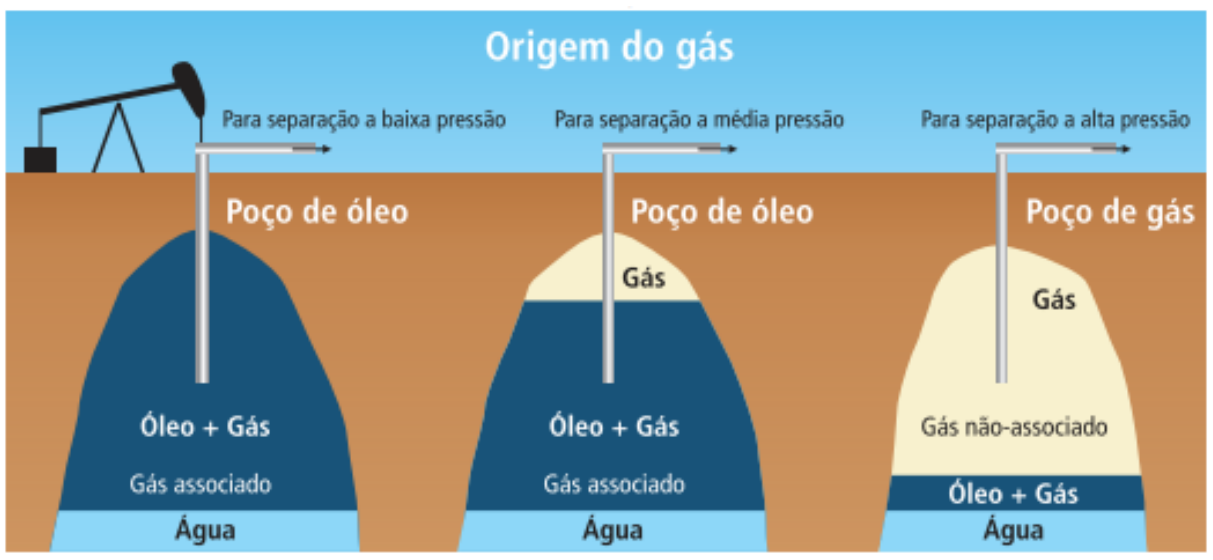

Figura 1. Classificação do gás natural quanto a sua origem

Fonte: Vieira et al. (2005)

A composição natural do GN pode variar de campo para campo conforme o tipo de matéria orgânica que lhe deu origem e conforme os processos naturais a que foi submetido (VIEIRA et al., 2005) (Tabela 1). Igualmente, a composição comercial do gás natural também é bastante diversificada, dependendo da composição do gás natural bruto, do processamento em unidades industriais, do mercado atendido, do uso final e do produto que se deseja (LOPES, 2003). Apesar desta variabilidade da composição, são parâmetros fundamentais que determinam a especificação comercial do gás natural: o seu teor de enxofre total, o teor de gás sulfídrico, o teor de gás carbônico, o teor de gases inertes, o ponto de orvalho da água, o ponto de orvalho dos hidrocarbonetos e o poder calorífico (SOUZA Jr. \& SOUZA, 2012).

Atualmente, as reservas provadas de gás natural se espalham por todos os continentes. $O$ GN pode ser encontrado em cerca de oitenta países, sendo que aproximadamente $71 \%$ das reservas mundiais estão situadas na Europa Oriental (ex-União Soviética e Oriente Médio), enquanto que a América Latina possui cerca de $5 \%$ do total mundial de reservas, as quais $84 \%$ estão na Venezuela, México e Argentina (REIS et al., 2005). Ainda segundo os autores, sobre o território brasileiro encontrasse aproximadamente 4,4 milhões de $\mathrm{km}^{2}$ em extensão de bacias sedimentares, representando $51,7 \%$ da porção territorial, sendo que $18,2 \%$ dessas bacias localizam-se no mar. A maior reserva provada de gás natural encontra-se na Rússia, com $27 \%$ do total mundial, seguida pelo Irã (15\%) e Qatar (14\%), ao passo que na América Latina, as maiores reservas estão localizadas na Venezuela (2,4\%) e na Bolívia (0,7\%) (PRATES et al., 2006).

Tabela 1. Composição de diferentes gases extraídos em diferentes regiões

\section{Características de alguns gases (porcentagem em volume)}




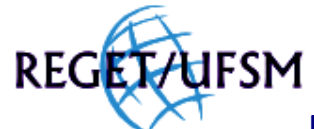

FIOREZE et al., v(10), no 10, p. 2251-2265, JAN-ABR, 2013.

Rev. Elet. em Gestão, Educação e Tecnologia Ambiental (e-ISSN: 2236-1170)

\begin{tabular}{ccccc}
\hline Componentes & Bacia de Campos (BR) & Guamaré (BR) & Bahia (BR) & Bolívia \\
\hline Metano $\left(\mathrm{C}_{1}\right)$ & 89,4 & 83,5 & 88,5 & 90,7 \\
Etano $\left(\mathrm{C}_{2}\right)$ & 6,7 & 11,0 & 9,2 & 6,1 \\
Propano $\left(\mathrm{C}_{3}\right)$ & 2,2 & 0,4 & 0,4 & 1,2 \\
Butano e Superiores $\left(\mathrm{C}_{4}\right)$ & 0,5 & $\mathrm{ND}$ & $\mathrm{ND}$ & $\mathrm{ND}$ \\
$\mathrm{H}_{2} \mathrm{~S}$ & traços & traços & Traços & traços \\
$\mathrm{CO}_{2}$ & 0,3 & 2,0 & 0,6 & 0,5 \\
$\mathrm{~N}_{2}$ & 0,8 & 3,2 & 1,2 & 1,4 \\
Poder calorífero superior $\left(\mathrm{kcla} / \mathrm{m}^{3}\right)$ & 0,623 & 0,644 & 0,615 & 0,607 \\
& 9,608 & 9,207 & 9,375 & 9,264 \\
\hline & Fonte: ABREU \& MARTINEZ (1999) & &
\end{tabular}

\subsection{Produção, Utilização e Mercado Mundial de Gás Natural}

O uso do gás natural como fonte de suprimento energético se deu principalmente a partir dos choques do petróleo, ocorridos nos anos de 1973 e 1979. Vinte anos após o primeiro choque, houve uma duplicação das reservas mundiais de gás natural, passado estas de 63,2 para 139,7 trilhões de metros cúbicos no período de 1975-1995 (GOMES, 1996). Segundo dados da Agência Nacional do Petróleo, Gás Natural e Biocombustíveis (ANP, 2010), no ano de 2008, as reservas provadas de gás natural no mundo somaram 185,1 trilhões de $\mathrm{m}^{3}$, sendo registrado um crescimento de 4,5\% em relação a 2007. Já no Brasil, houve um decréscimo de 0,2\% entre 2007 e 2008 nas reservas provadas, o que equivale a 364 bilhões de $\mathrm{m}^{3}$ (DOMINGUES, 2009).

Diferentemente do petróleo, o gás natural não possui propriamente um mercado mundial, mas sim mercados regionais. Dentre esses, se destacam os mercados da Europa, da América do Norte e da Ásia, cada um com suas características próprias no que tange à estrutura da oferta e da demanda do produto, o que, por sua vez, tem relação direta com os preços do gás natural nessas áreas (SOUSA, 2010).

Bem como outros combustíveis fósseis, como o petróleo, o gás natural não é utilizado em sua forma bruta, necessitando de etapas prévias de processamento. Seu processamento ocorre a partir de sua queima, pelo aproveitamento do conteúdo térmico dos gases de sua combustão, podendo ocorrer de forma direta (utilizando os gases de combustão como fluídos de transferência), ou de forma indireta (vapor d'água) (GOMES, 1996). No Brasil, seu processamento consiste em tornar a composição do $\mathrm{GN}$ de acordo com as especificações determinadas na portaria ANP 104/2002, para que o mesmo possa ser comercializado em todo o território nacional.

Para o aproveitamento do GN, os gases butano e propano são liquefeitos, gerando assim o chamado gás liquefeito de petróleo (GLP), o qual é armazenado em tanques pressurizados para uso em áreas onde não existe distribuição por rede, sendo o restante do gás (metano) distribuído em redes (BRAGA et al., 2005). A liquefação do gás natural consiste em uma séria de processos cujo objetivo é converter o gás natural gasoso para o estado líquido, situação em que ocupa um volume cerca de 600 vezes menor (ANP, 2010). Essa conversão de estados físicos do gás natural é de suma importância, uma vez que seu estado físico gasoso não permite a estocagem de grandes volumes a custos competitivos, visto a tecnologia disponível, fato este que leva à produção e 


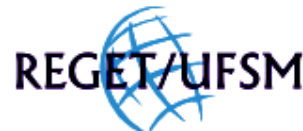

FIOREZE et al., v(10), no 10, p. 2251-2265, JAN-ABR, 2013.

Rev. Elet. em Gestão, Educação e Tecnologia Ambiental (e-ISSN: 2236-1170)

consumo simultâneos na maior parte dos casos, exigindo elevados investimentos em ativos específicos (PRATES et al., 2005).

Para Praça (2003), em linhas gerais, a cadeia produtiva do gás natural pode ser dividida em cinco atividades interligadas. A primeira delas é a exploração, que consiste no reconhecimento e estudo das formações propícias ao acúmulo de petróleo e/ou gás natural, comprovadas através da perfuração dos poços. A segunda é a produção, na qual o GN passa por separadores para a retirada da água e dos hidrocarbonetos no estado líquido. A produção pode ocorrer em terra (onshore) ou em mar (offshore), sendo esta última a responsável pela maior parte da produção brasileira. A terceira atividade consiste no processamento, que ocorre em Unidades de Processamento de Gás Natural (UPGN), onde o produto é desidratado e fracionado, gerando três subprodutos: o gás natural processado, formado a partir do metano e etano, o GLP, originado do propano e do butano e a gasolina natural. A quarta é a de transporte, uma das mais críticas do processo, podendo o gás ser transportado no estado gasoso e líquido. A última atividade é a distribuição, geralmente realizada através de gasodutos, levando o produto final aos consumidores residencial, comercial, industrial ou automotivo.

Segundo a ANP (2010), a produção de GNL compreende as seguintes atividades: a) exploração, produção e processamento do gás natural; b) liquefação; c) transporte; d) armazenamento; e) regaseificação; f) distribuição ao mercado consumidor (Figura 2). Ainda conforme a ANP, a extração e produção de gás natural são economicamente viáveis quando a relação entre a distancia do transporte via dutos e os locais de consumo se apresenta de maneira positiva, o que justifica a sua produção.

A utilização futura de gás natural deve ser favorecida em detrimento de seus principais concorrentes em função de dois aspectos: devido ao gás natural permanecer com preços inferiores aos do petróleo e as crescentes pressões em favor do combate às mudanças climáticas, que vão estimular o crescimento da participação no mercado de combustíveis que emitam menos gases de efeito estufa (SOUSA, 2010).

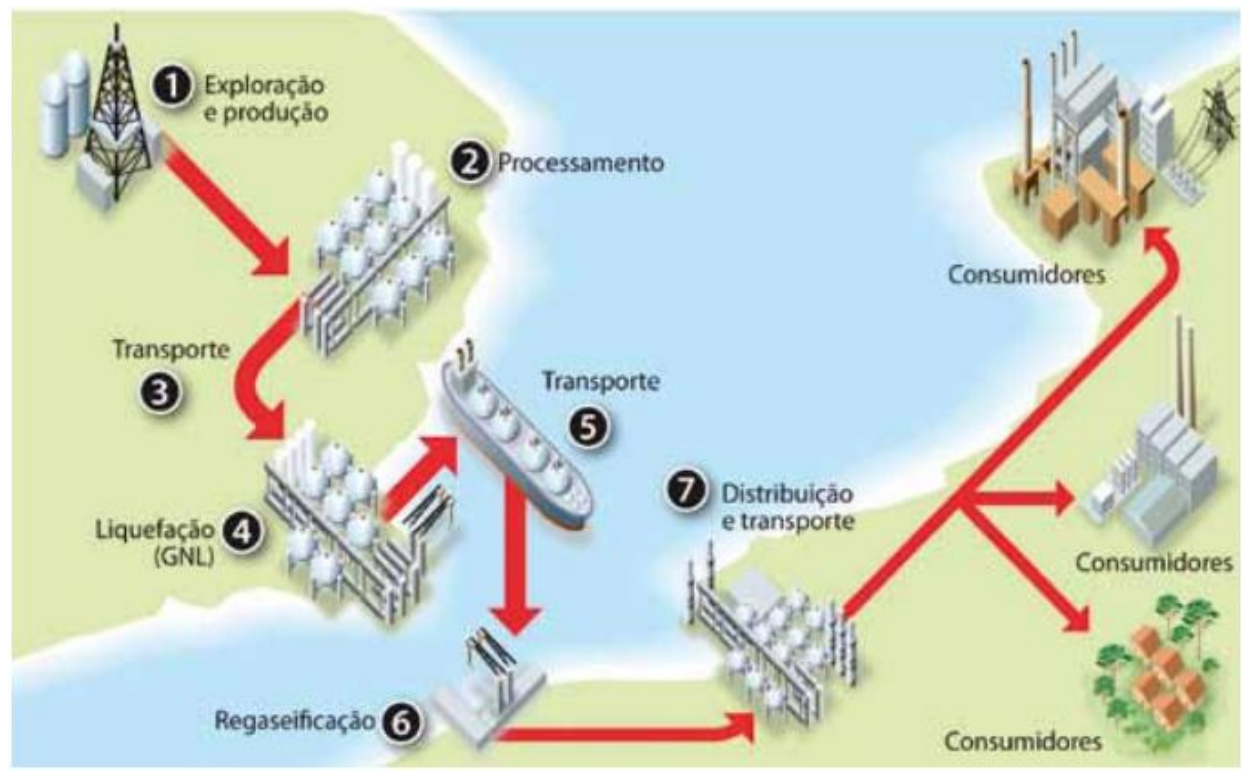

Figura 2. Cadeia de valor do GNL 
REGEXftFSM

Rev. Elet. em Gestão, Educação e Tecnologia Ambiental (e-ISSN: 2236-1170)

Fonte: ANP (2010)

\subsection{O Cenário Brasileiro de Gás Natural}

O mercado brasileiro de gás natural é relativamente recente. A utilização de GN em território nacional teve início por volta de 1940, dada às descobertas de óleo e gás na Bahia, atendendo as indústrias do Recôncavo Baiano (PARO, 2005). No início dos anos 1980, houve a expansão do mercado de gás natural a partir da exploração da Bacia de Campos, no Estado do Rio de Janeiro, a qual proporcionou um aumento da participação do GN na matriz energética nacional em 3\% a partir de 1997, sendo grandemente favorecido pelo término do gasoduto Bolívia-Brasil (GasBol), com capacidade máxima de transportar 30 milhões $\mathrm{m}^{3} /$ dia (MANOEL, 2006; PRATES et al., 2006). Porém, por muitos anos, o GN foi considerado como um subproduto do petróleo, sendo utilizado principalmente para a reinjeção nos poços visando a potencialização da produção dos mesmos, ou então queimado em tochas nas plataformas de produção (PARO, 2005).

No ano de 1987 foi instituído pelo governo brasileiro o Plano Nacional para o Gás Natural (PNGN), com o objetivo de introduzi-lo na matriz energética brasileira. Este plano visava à elevação da participação do $G N$ a até $10 \%$ no ano 2000 , o que não foi cumprido, apesar de crescerem os argumentos a favor da expansão e consolidação do mercado nacional de GN devido à crescente descoberta de reservas provadas (PARO, 2005; SANTOS et al., 2002). A privatização do setor elétrico no Brasil, e a crise elétrica deflagrada, impulsionou o governo brasileiro a incrementar a expansão da potência instalada através de usinas termelétricas alimentadas por gás natural (PRAÇA, 2003). Até os anos 1990, o mercado brasileiro de gás estava centrado em poucos estados, principalmente Rio de Janeiro, São Paulo e Bahia, e as reservas, além de não representativas, eram pouco exploradas e se concentravam em alto mar, geralmente com o acúmulo de gás associado ao petróleo, sendo somente a partir dos anos 2000 observado um crescimento significativo do mercado nacional (PRATES et al., 2006). Para Burghetti (2010), o Brasil caminha para um cenário potencial na produção de gás natural, devido às descobertas da fronteira do Pré-Sal, podendo inclusive se deparar com um mercado insuficiente para absorver todo o gás produzido. Disponível em uma rede de gasodutos em franca expansão (Figura 3), o gás natural vem ocupando um espaço cada vez mais relevante na matriz energética brasileira. 


\section{REGETAUFSM}

FIOREZE et al., v(10), no 10, p. 2251-2265, JAN-ABR, 2013.

Rev. Elet. em Gestão, Educação e Tecnologia Ambiental (e-ISSN: 2236-1170)

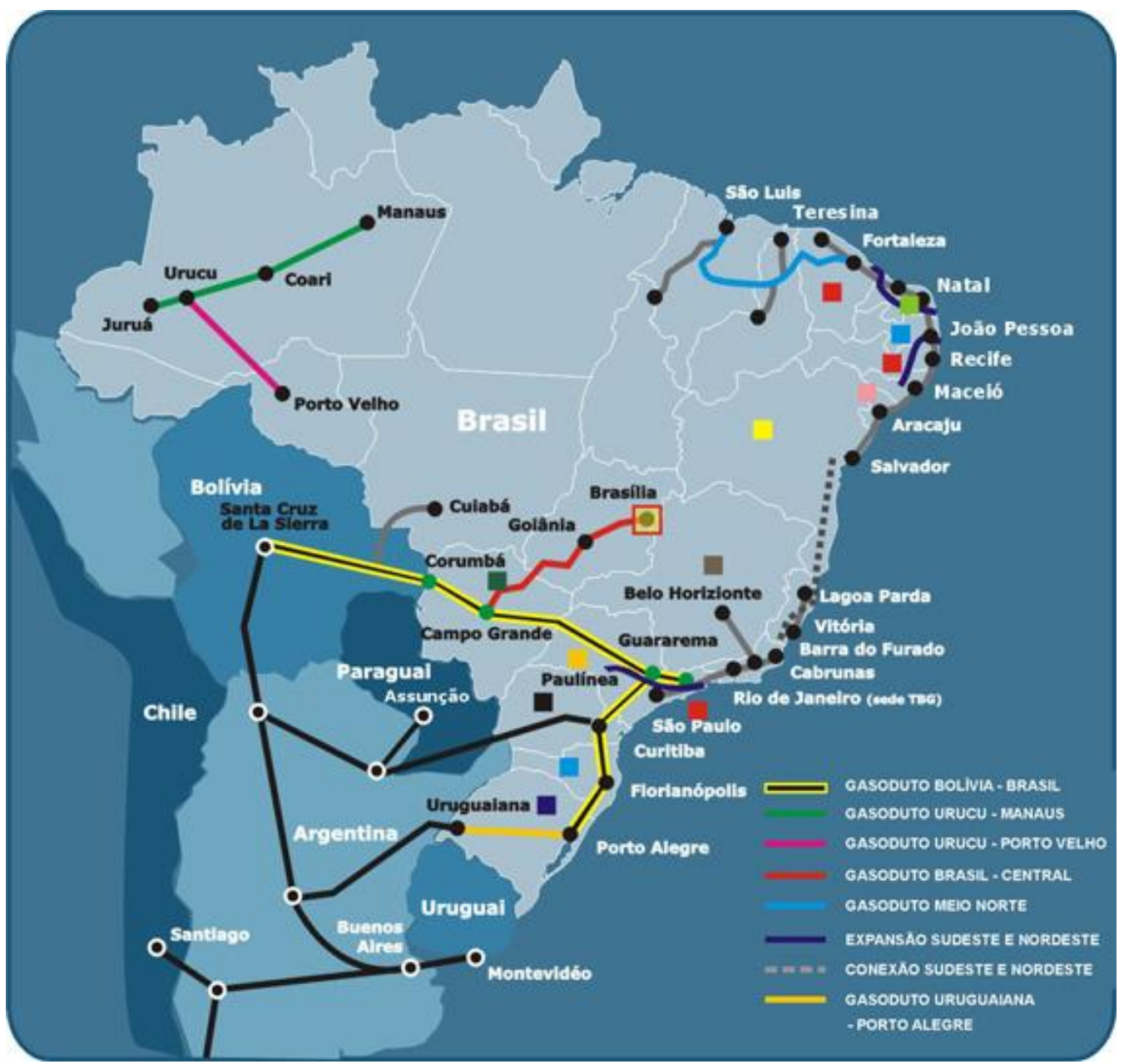

Figura 3. Principais gasodutos instalados na América do Sul

Fonte: ANP (2010)

Segundo dados da Resenha Energética Brasileira 2009, referente ao ano de 2008, o gás natural representa cerca de $10,2 \%$ da oferta interna de energia (ANP, 2010). A evolução nas vendas de gás natural entre 2000 e 2008 pode ser verificada na Tabela 2.

Tabela 2. Vendas médias mensais de gás das distribuidoras por segmento, em $\mathrm{mil} \mathrm{m}^{3} / \mathrm{dia}$.

\begin{tabular}{cccccccccc}
\hline & $\mathbf{2 0 0 0}$ & $\mathbf{2 0 0 1}$ & $\mathbf{2 0 0 2}$ & $\mathbf{2 0 0 3}$ & $\mathbf{2 0 0 4}$ & $\mathbf{2 0 0 5}$ & $\mathbf{2 0 0 6}$ & $\mathbf{2 0 0 7}$ & $\mathbf{2 0 0 8}$ \\
\hline Industrial & $\begin{array}{c}12.917 \\
1\end{array}$ & $\begin{array}{c}12.828, \\
6\end{array}$ & $\begin{array}{c}16.579, \\
7\end{array}$ & $\begin{array}{c}18.459, \\
6\end{array}$ & $\begin{array}{c}20.256, \\
9\end{array}$ & $\begin{array}{c}22.487, \\
2\end{array}$ & $\begin{array}{c}24.265, \\
5\end{array}$ & $\begin{array}{c}25.267, \\
2\end{array}$ & $\begin{array}{c}25.743, \\
9\end{array}$ \\
\hline $\begin{array}{c}\text { Automoti } \\
\text { vo }\end{array}$ & 992,6 & $1.752,4$ & $2.688,9$ & $3.646,0$ & $4.321,7$ & $5.295,7$ & $6.308,8$ & $6.986,3$ & $6.722,0$ \\
\hline
\end{tabular}




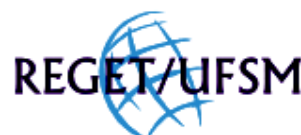

FIOREZE et al., v(10), no 10, p. 2251-2265, JAN-ABR, 2013.

Rev. Elet. em Gestão, Educação e Tecnologia Ambiental (e-ISSN: 2236-1170)

\begin{tabular}{cccccccccc}
\hline $\begin{array}{c}\text { Residenci } \\
\text { al }\end{array}$ & 495,8 & 462,6 & 491,5 & 538,8 & 593,0 & 607,3 & 649,8 & 661,5 & 597,2 \\
\hline Comercial & 287,6 & 304,3 & 261,9 & 407,4 & 447,5 & 706,6 & 556,4 & 582,6 & 587,7 \\
\hline $\begin{array}{c}\text { Geração } \\
\text { (inclui }\end{array}$ & $2.115,6$ & $5.271,3$ & $6.956,7$ & $6.100,2$ & $\begin{array}{c}10.322, \\
6\end{array}$ & $\begin{array}{c}11.349, \\
6\end{array}$ & $9.670,4$ & $7.166,3$ & $\begin{array}{c}15.915, \\
\text { Cogeraçã } \\
\text { o) }\end{array}$ \\
\hline $\begin{array}{c}\text { Outros } \\
\text { (inclui } \\
\text { GNC) }\end{array}$ & - & - & - & - & - & 165,3 & 310,3 & 256,5 & 172,9 \\
\hline Total & 16.849 & 22.619 & 27.079 & 29.152 & 35.942 & 40.972 & 41.761 & 41.029 & 49.739 \\
\hline
\end{tabular}

Conforme observado, o setor que mais consome gás natural no Brasil é o industrial, seguido pelo de geração elétrica. Em menor escala, estão os setores automotivo, residencial e comercial. É observada uma taxa média de crescimento anual de $14,5 \%$ a.a. para o conjunto do período. Os seguimentos que mais contribuíram para tal crescimento foram os de geração elétrica $(28,4 \%$ a.a.) e o automotivo ( $27 \%$ a.a.), seguido pelos setores industrial $(9,0 \%$ a.a.) e comercial (9,3\% a.a.). Considerando o período de $2007 / 2008$, a taxa de crescimento da demanda por gás natural atingiu $21,2 \%$ a.a., em especial devido ao grande aumento do consumo de gás destinado à geração elétrica, que em grande parte pode-se explicar devido a maior necessidade de despacho das usinas térmicas a gás natural.

Os incentivos e o programa de massificação do uso de gás natural contribuíram de maneira significativa para aumentar sua competitividade no País e para sua inserção na matriz energética, porém, proporcionou o cenário das variações no preço do energético. Foi a parti de 2005 que a elevação nos preços de gás começou a ser sentida, sendo que por volta de 2008 esse aumento foi intensificado tanto para o gás natural de origem nacional quanto para o importado (ANP, 2010). Através da Figura 4 pode-se perceber que foi no ano de 2008 o período de maior inflação. 
Rev. Elet. em Gestão, Educação e Tecnologia Ambiental (e-ISSN: 2236-1170)

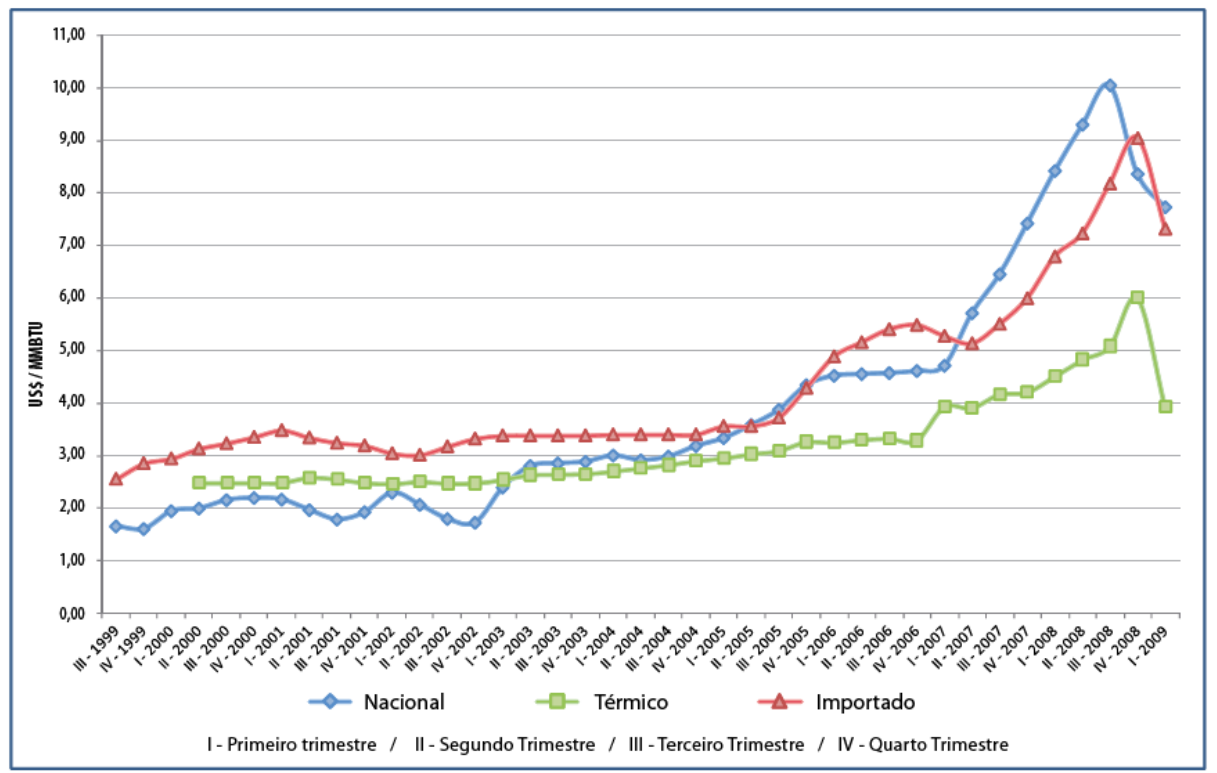

Figura 4. Preços no city gate do gás natural nacional, importado e do programa PPT, em US\$/milhão de BTUs referentes ao período do 3 trimestre de 1999 ao 1 은 trimestre de 2009.

Fonte: ANP, 2010.

Em reservas, o Brasil possui comprovadamente cerca de 331,9 bilhões de $\mathrm{m}^{3}$ de gás natural, sendo que a maior parte (63\% das reservas) encontra-se no mar (Figura 5) (Reis et al., 2005). Ainda segundo os autores, os estados do Rio de Janeiro, Bahia e Amazonas, juntos, somam $76 \%$ de todas as reservas de gás natural do Brasil, sendo apenas a Bacia de Campos (RJ) responsável por quase $40 \%$ do total de gás natural produzido. De acordo com Goldemberg \& Lucon (2007), as reservas de gás natural brasileira são 33\% superiores às de 2003 e equivalem a dezenove anos da atual produção.

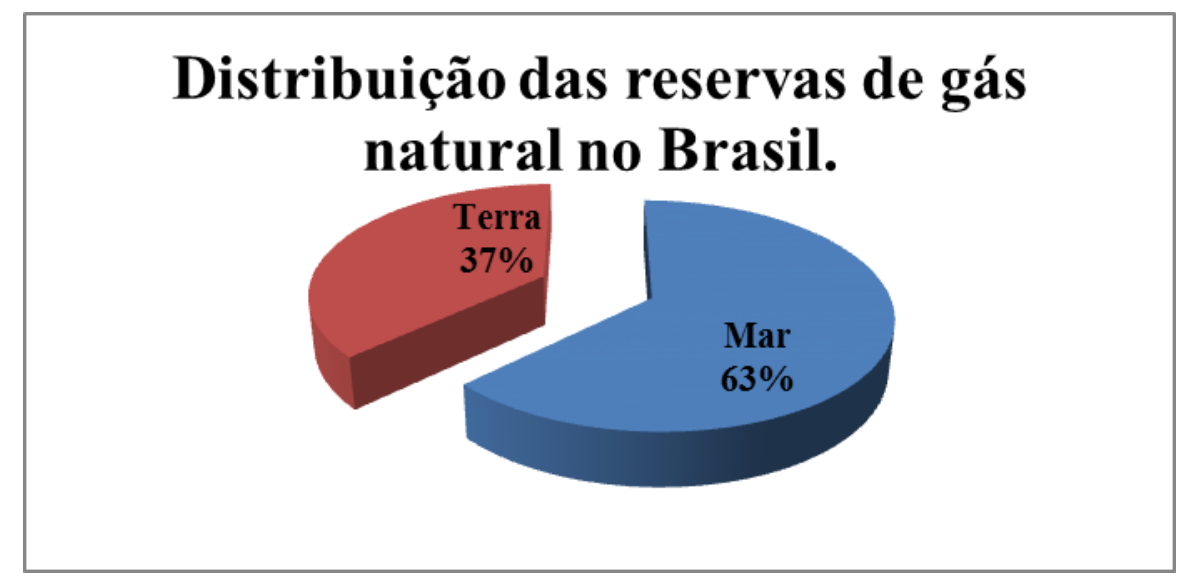

Figura 5. Distribuição das reservas de GN no Brasil, 2002 Fonte: Adaptado de Reis et al. (2005)

Os múltiplos usos do gás natural, aliados à crescente pressão da sociedade para o uso de energias que causem menos impacto ambiental, e a recente descoberta de vultosas reservas na 


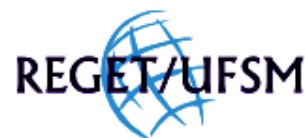

FIOREZE et al., v(10), no 10, p. 2251-2265, JAN-ABR, 2013.

Rev. Elet. em Gestão, Educação e Tecnologia Ambiental (e-ISSN: 2236-1170)

região do Pré-Sal, têm contribuído para o incremento no uso do GN em diversos mercados. A projeção da matriz energética brasileira para 2020 contempla um aumento da participação do GN para $14,4 \%$ em relação aos $10,6 \%$ de 2011 , enquanto o petróleo, apesar de continuar tendo um peso expressivo, diminuirá sua participação de 36,9\% em 2011 para 31,8\% em 2020 (MARQUES, 2012). A Figura 6 demostra o balanço nacional de GN.

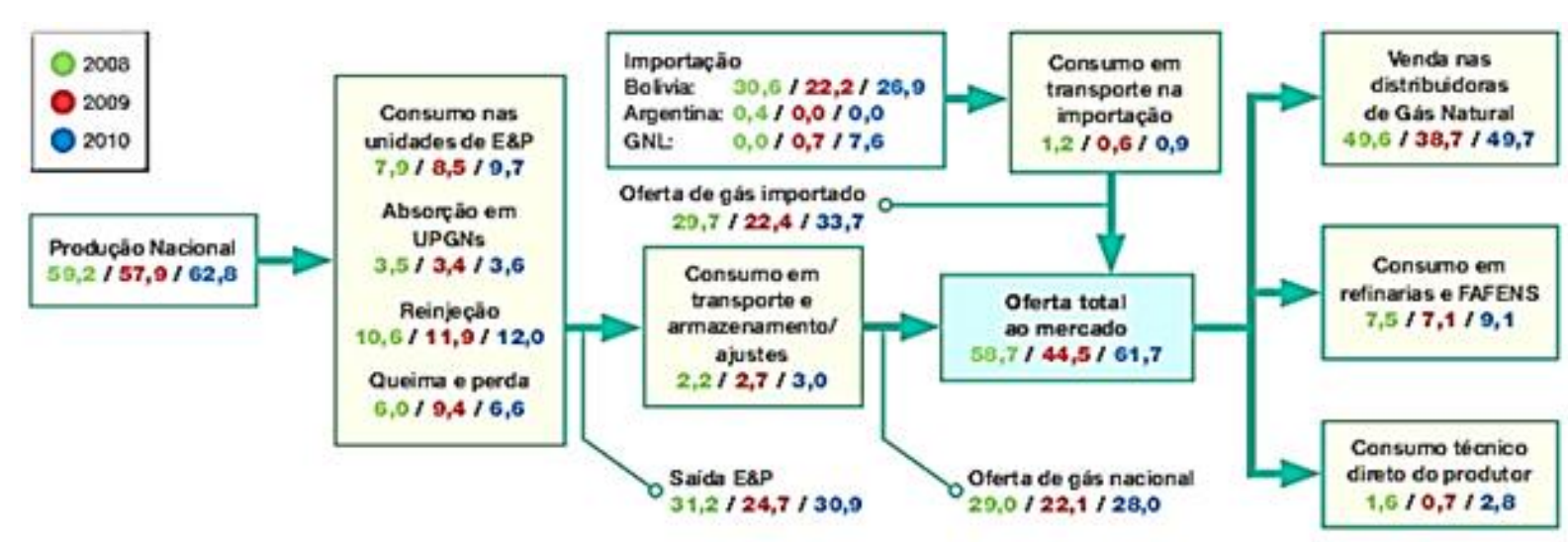

Figura 6. Balanço de gás natural no Brasil (milhões de $\mathrm{m}^{3} /$ dia)

Fonte: MME (2011)

\subsection{Base Legal para Produção e Comercialização de Gás Natural no Brasil}

O $\S 2^{\circ}$ do artigo 25 da Constituição Federal, que trata da distribuição de gás natural canalizado, prescreve que "cabe aos Estados explorar diretamente, ou mediante concessão, os serviços locais de gás canalizado, na forma da lei, vedada a edição de medida provisória para a sua regulamentação". Dessa forma, ficou estabelecida como responsabilidade dos estados a atividade de distribuição de gás natural em território brasileiro, sendo esta atividade enquadrada no âmbito de serviços públicos. Porém, com a Emenda Constitucional $n^{\circ} 05 / 95$, passou também a ser possível à outorga da concessão a companhias particulares (COSTA, 2006). Já o artigo 177 da CF, em seu parágrafo primeiro, estabelece que a União poderá contratar empresas estatais ou privadas, uma vez observadas as condições previstas em lei, para realização de atividades de pesquisa e lavra das jazidas de petróleo e gás natural, a refinação de petróleo nacional ou importado, a importação e exportação dos produtos e derivados de petróleo e gás natural e o transporte marítimo ou por via duto desses energéticos.

Para regulamentar o disposto no artigo 177 da Constituição Federal, foi editada, em 6 de agosto de 1997, a Lei $n^{\circ}$ 9.478, conhecida como Lei do Petróleo, a qual dispõe sobre a política energética nacional e institui o Conselho Nacional de Política Energética (CNPE) e a Agência Nacional do Petróleo (ANP), hoje denominada Agência Nacional do Petróleo, Gás Natural e Biocombustíveis (COSTA, 2006; VALLE \& FARIAS FILHO, 2008). As diretrizes da Agência são emanadas do Conselho Nacional de Política Energética (CNPE) e estão em conformidade com os interesses do País. Nesse sentido, a ANP tem criado várias regulamentações (portarias) para atender as necessidades do setor petróleo, gás natural e de biocombustíveis (VALLE \& FARIAS FILHO, 2008). 


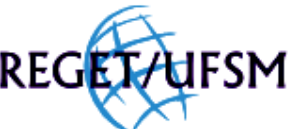

FIOREZE et al., v(10), no 10, p. 2251-2265, JAN-ABR, 2013.

Rev. Elet. em Gestão, Educação e Tecnologia Ambiental (e-ISSN: 2236-1170)

A partir da publicação da Lei no 11.909 , de 4 de março de 2009, a comercialização de gás natural ficou definida como a "atividade de compra e venda de gás natural, realizada por meio da celebração de contratos negociados entre as partes e registrados na ANP, ressalvado o disposto no $\S 2 \circ$ do art. 25 da Constituição Federal” (Art. 2으, VIII).

Já a Resolução ANP n.o 52/2011 regulamenta os dispositivos atinentes à comercialização de gás natural, trazidos pela Lei no 11.909/2009 e pelo Decreto $n$ 으 7.382/2010, a saber: a autorização da prática da atividade de comercialização de gás natural, dentro da esfera de competência da União, o registro de agente vendedor e o registro de contratos de compra e venda de gás natural.

\section{CONCLUSÕES}

O gás natural é hoje responsável por pouco mais de $10 \%$ da produção energética brasileira, adquirindo cada vez mais importância devido ao crescimento das demandas por energia e ao fato de ser menos intensivo em carbono que o petróleo e o carvão mineral. Ainda, sua exploração e utilização não sofrem interferência com as sazonalidades climáticas e temporais, as quais desfavorecem muitas vezes o uso de centrais hidrelétricas, responsáveis pela maior parte da produção energética do Brasil.

Devido às ultimas descobertas, em especial a camada Pré-Sal na Bacia de Santos, o gás natural pode crescer consideravelmente sua participação na matriz energética nacional até o ano de 2020, enquanto que o petróleo sofrerá diminuições de sua participação. Desta forma, o GN vai se consolidando como um energético de essencial utilização na matriz energética nacional, atendendo inclusive aos requisitos de um mercado cada vez mais exigente quanto aos impactos ambientais gerados na utilização.

\section{REFERÊNCIAS}

ABREU, P. L.; MARTINEZ, J. A. Gás natural - o combustível do novo milênio. Plural Comunicação. Porto Alegre, p. 9-70, 1999.

ANEEL. Agência Nacional de Energia Elétrica. Gás Natural. 2005. Disponível em: <http://www.aneel.gov.br/aplicacoes/atlas/pdf/09-Gas_Natural(2).pdf>. Acesso em: 26 nov. 2012.

ANP. Agência Nacional do Petróleo, Gás Natural e Biocombustíveis. O gás natural liquefeito no Brasil. Experiência da ANP na implantação dos projetos de importação de GNL. Rio de Janeiro, séries tem éticas ANP - $n^{\circ} 4,2010$.

ANP. Agência Nacional de Petróleo. Comercialização de gás natural. 2012 . Disponível em: <http://www.anp.gov.br/?id=2666>. Acesso em: 26 dez. 2012.

ARRUDA, M. Z. de. Análise de combustíveis de caldeiras. Trabalho de Conclusão de Curso (Graduação em Engenharia Ambiental) - Passo Fundo: UPF, 2009.

BAIRD, C.; CANN, M. Química ambiental. 4 ed. Porto Alegre: Bookman, 4 ed. 844 p., 2011.

BRAGA, B.; HESPANHOL, I.; CONEJO, J. G. L., et al. Introdução à Engenharia Ambiental. São Paulo: Pearson Prentice Hall, 2 ed., 2005. 


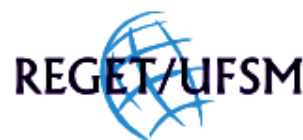

FIOREZE et al., v(10), no 10, p. 2251-2265, JAN-ABR, 2013.

Rev. Elet. em Gestão, Educação e Tecnologia Ambiental (e-ISSN: 2236-1170)

BRASIL. Constituição da República Federativa do Brasil de 1988. Diário Oficial da União, Brasília, DF, 05 out. 1988, p.1.

BURGHETTI, B. S. Perspectivas estratégicas para grandes consumidores industriais frente às mudanças regulatórias com a inclusão do livre acesso às redes de distribuição de gás natural. Dissertação (Mestrado em Energia) - São Paulo: EP/USP, 2010.

COSTA, H. K. de M. A regulação do livre acesso na distribuição de gás natural canalizado: o caso de São Paulo. Dissertação (Mestrado em Energia) - São Paulo: PIPGE/USP, 2006.

DOMINGUES, J. C. de A. Perda do valor de recuperação em ativos de exploração e produção de petróleo e gás. Dissertação (Mestrado em Contabilidade) - São Paulo: DC/USP, 2009.

FERREIRA, R. S. Desenvolvimento de materiais poliméricos uretânicos para purificação de gás natural: remoção de mercúrio e compostos à base de enxofre. Dissertação (Mestrado em Química) - Curitiba: UFPR, 2006.

GOLDEMBERG, J.; LUCON, O. Energia e meio ambiente no Brasil. Estudos Avançados, São Paulo, v. 21, n. 59, p. 7-20, 2007.

GOMES, I. C. Uma análise do mercado e do preço competitivo de gás natural em São Paulo. Dissertação (Mestrado em Energia) - São Paulo: USP, 1996.

GOMES, M. J. Estudo do mercado brasileiro de gás natural contextualizado ao Shale Gás. Trabalho de Conclusão de Curso (Graduação em Engenharia Química) - Porto Alegre: DEQUI/UFRGS, 2011.

KOZERSKI, G. R.; HESS, S. C. Estimativa dos poluentes emitidos pelos ônibus e micro-ônibus de Campo Grande/MS, empregando como combustível diesel, biodiesel ou gás natural. Engenharia Sanitária e Ambiental, Rio de Janeiro; v. 11, n. 2, p. 113-117, abr./jun. 2006.

LAUREANO, F. H. G. C. A Indústria de Gás Natural no Brasil e a Viabilização de seu Desenvolvimento. Monografia (Bacharelado em Economia) - Rio de Janeiro: IE/UFRJ, 2002.

LOPES, F. W. B. Dessulfurização do gás natural utilizando sistemas microemulsionados. Dissertação (Mestrado em Engenharia Química) - Natal: PPGEQ/UFRN, 2003.

MANOEL, C. O. Aspectos Regulatórios e Modelos Contratuais Aplicáveis ao Mercado de Distribuição de Gás Natural a Granel (Gás Natural Comprimido - GNC, e Gás Natural Liquefeito - GNL) no Brasil. Dissertação (Mestrado em Energia) - São Paulo: PIPGE/USP, 2006.

MARQUES, F. R. Gás natural e descarbonização da economia brasileira. BSP, São Paulo, jul., 2012.

MATHIAS, M. C. P. P. A Formação da Indústria Global de Gás Natural: Definição, Condicionantes e Desafios. Tese (Doutorado em Ciências em Planejamento Energético) - Rio de Janeiro: COOPE/UFRJ, 2008.

PARO, A de C. Estudo da contribuição do gás natural no setor elétrico - uma análise de cenários de sua expansão nos setores de geração termelétrica, cogeração e residencial. Dissertação (Mestrado em Engenharia Elétrica) - São Paulo: EP/USP, 2005.

POULALLION, P. Manual do gás natural. Editado pelo Conselho para Assuntos de Energia - COASE, 1986.

PRAÇA, E. R. Distribuição de gás natural no Brasil: um enfoque crítico e de minimização de custos. Dissertação (Mestrado em Ciências) - Fortaleza: DET/UFCE, 2003. 


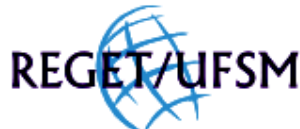

FIOREZE et al., v(10), no 10, p. 2251-2265, JAN-ABR, 2013.

Rev. Elet. em Gestão, Educação e Tecnologia Ambiental (e-ISSN: 2236-1170)

PRATES, C. T.; COSTA, R. C. da; PASTORIZA, F. A. Setor de Petróleo e Gás Natural: Perfil dos Investimentos. BNDES Setorial, Rio de Janeiro, n. 22, p. 3-28, set. 2005.

PRATES, C. P. T.; PIEROBON, E. C.; COSTA, R. C. da.; FIGUEIREDO, V. S. de. Evolução da oferta e da demanda de gás natural no Brasil. BNDES Setorial, Rio de Janeiro, n. 24, p. 35-68, set. 2006.

REIS, L. B. dos; FADIGAS, E. A. A.; CARVALHO, C. E. Energia, Recursos Naturais e a Prática do Desenvolvimento Sustentável. São Paulo: Manole, 2. ed, 2005.

ROCHA, A. M. A. Análise experimental em chamas difusivas pulsadas de gás natural. Dissertação (Mestrado em Engenharia e Tecnologia Espaciais) - São José dos Campos: INPE, 2002.

SANTANA, C. N. Síntese de Fischer-Tropsch: Processos Industriais e Adsorção de CO em Aglomerados Metálicos. Projeto Final de Curso (Graduação em Engenharia Química) - Rio de Janeiro: UFRJ/EQ, 2006.

SANTOS, E. M. Dos; FAGÁ, M. T. W.; BARUFI, C. B.; POULALLION, P. L. Gás natural: a construção de uma nova civilização. Estudos Avançados, São Paulo; v. 21, n. 59, p. 67-90, 2007.

SANTOS, E. M. dos; ZAMALlOA, G. C.; VILLANUEVA, L. D.; FAGÁ, M. T. W. Gás Natural: estratégias para uma energia nova no Brasil. São Paulo: Annablume, Fapesp, Petrobrás, 2002.

SOUSA, F. J. R. O setor de gás natural do mundo. Brasília, Nota Técnica, 2010.

SOUZA Jr, E. S. de; SOUZA, M. da S. R. de. Gás natural veicular. Projeto Universidade Petrobras e IF Fluminense, v.2, n.1, p. 335-340, 2012.

VALLE, M. A. N. do.; FARIAS FILHO, J. R. de. $\mathrm{O}$ gás natural como um dos retratos da gestão energética brasileira. In: IV Congresso Nacional de Excelência em Gestão - Responsabilidade Socioambiental das Organizações Brasileiras. Niterói, agosto, 2008.

VIEIRA, P. L., GARCIA, C. B., GUIMARÃES H., B., TORRES, E. A., PEREIRA, O. L. S. Gás natural: benefícios ambientais no Estado da Bahia. Salvador: Solisluna Design e Editora, 132 p., 2005. 